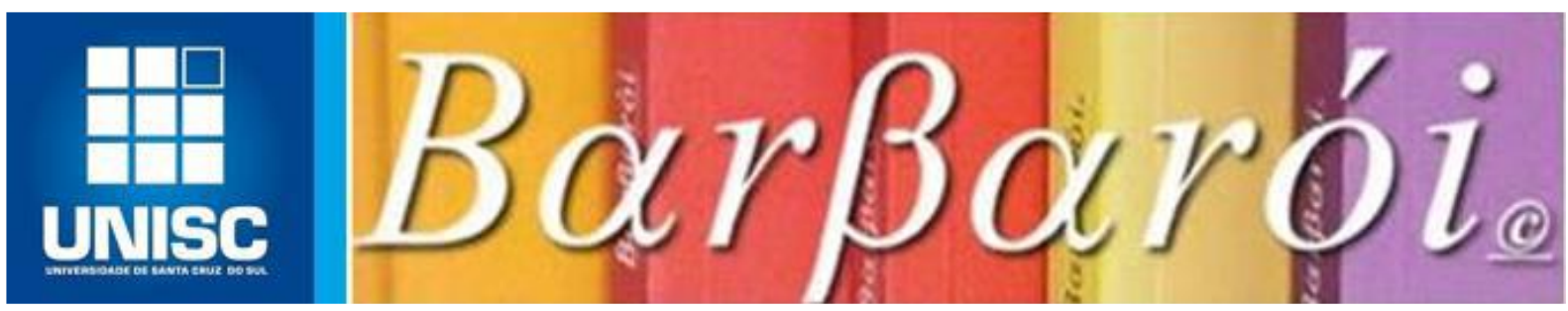

\title{
“O MERCADO DE TRABALHO É MUITO CRUEL": REPRESENTAÇÕES SOCIAIS DE MULHERES EM SOFRIMENTO PSÍQUICO
}

\section{DOI: http://dx.doi.org/10.17058/barbaroi.v0i57.15256}

\author{
$*$ \\ Marieli Mezari Vitali \\ Universidade Federal de Santa Catarina - UFSC - Brasil \\ Camila Maffioleti Cavaler \\ Universidade Federal de Santa Catarina - UFSC - Brasil \\ Jacks Soratto \\ Universidade do Extremo Sul Catarinense - UNESC - Brasil \\ Amanda Castro \\ Universidade do Extremo Sul Catarinense - UNESC - Brasil

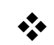

\section{Resumo}

O presente estudo teve como objetivo investigar as representações sociais sobre trabalho para pessoas em sofrimento psíquico. Trata-se de uma pesquisa-ação, de abordagem qualitativa e exploratória, desenvolvida por grupo no formato de sociodrama e ancorada na Teoria das Representações Sociais. Foram realizados 5 encontros com duração de 1 hora cada, com a participação de 6 usuárias de um Centro de Atenção Psicossocial. A análise de dados foi realizada com análise de conteúdo do tipo categorial, com o auxílio do software Atlas.ti. Os resultados evidenciaram 7 categorias que envolvem os aspectos adoecedores do trabalho, significado do trabalho, perspectivas de futuro, sonho de infância e adolescência, imagens relacionadas ao trabalho e sociabilidade. As representações sociais do trabalho para as participantes estão ancoradas em suas experiências negativas de trabalho e objetificadas na imagem do dinheiro, que garante a subsistência e o lazer.

Palavras chaves: Representação Social. Trabalho. Saúde Mental.

\section{Introdução}

Marx (2016) concebe o trabalho como um processo no qual homem e natureza estão ligados. O homem através da sua ação é o responsável pelo intercâmbio material com a natureza, modificando a natureza externa, mas, ao mesmo tempo, modificando a si mesmo, sua própria natureza. De acordo com o autor, o processo de trabalho parte do pressuposto de que a Barbarói, Santa Cruz do Sul, n. 57, p.<44-64>,jul./dez. 2020 
atividade do homem promove uma transformação no objeto para um fim prévio, sendo que o indivíduo dispõe de um instrumental para sua realização.

Para Marx (2016), o trabalho pode ser considerado um importante ambiente social, pois não produz apenas a mercadoria. Produz a si mesmo e ao trabalhador na medida em que possibilita a transformação de um bem natural em elemento social de utilidade para os indivíduos. Ainda, o autor dispõe que a inauguração da sociedade capitalista fez com que o trabalhador também fosse transformado em uma mercadoria, tendo em vista que vende sua força de trabalho devido à necessidade de um salário.

Nesse modelo de sociedade, por vezes, o trabalho deixa de dar sentido a realização humana e passa a ser usado como garantia de sobrevivência. No entanto, faz-se necessário pontuar que nem todo trabalho social garante um valor monetário (MARX, 2010). É o que acontece, por exemplo, com o trabalho reprodutivo, que apesar de não produzir valor financeiro garante a manutenção da produção capitalista (FEDERICI, 2018). A divisão entre esses dois modos de trabalho culmina na divisão sexual do trabalho, em que majoritariamente mulheres exercem o trabalho reprodutivo não remunerado, enquanto homens produzem mais-valia através do trabalho produtivo (MELLO; CASTILHO, 2009).

A associação entre o suposto lugar "natural" das mulheres no trabalho reprodutivo, faz com que mesmo quando a mulher não execute as tarefas domésticas da casa, a pessoa contratada por ela para realizar o trabalho reprodutivo seja uma mulher. No ano de $200992 \%$ das trabalhadoras domésticas eram mulheres e 63,4\% eram negras (ANDRADE, 2016). O recorte racial também tem se mostrado um importante fator de exclusão social, visto que os homens brancos ocupam o topo da pirâmide monetária assalariada, enquanto mulheres negras ocupam sua base (IPEA, 2017).

Logo, há uma iminente necessidade de pensar o mercado de trabalho assalariado a partir da interseccionalidade de opressões à que os indivíduos estão expostos. Em um contexto em que o trabalhador é uma mercadoria, o empregador pode escolher quem deseja contratar de acordo com os atributos desejados e eliminar os indesejados. É o que acontece quando cruzamos raça, classe, gênero a categoria transtorno psíquico. Afinal, a identidade social de um indivíduo está relacionada aos atributos que ele apresenta e que são considerados importantes no ambiente social no qual está inserido ou que busca adentrar. Portanto, na lógica de mercado os atributos definem se um indivíduo é adequado ou não para ser incluído em algum espaço, caso não se enquadre no estereótipo esperado é comum que ocorra a exclusão do mesmo (GOFFMAN, 1988). 
Ao adotar uma perspectiva Marxista, entende-se que o trabalho é central na vida dos indivíduos devido sua capacidade organizadora na estruturação das demais relações sociais, como harmonia familiar e respeito do grupo em que está inserido. Além de ser visto como forma de aliviar a dor e sofrimento de outras áreas da vida, por exemplo, a vivência com diagnóstico de transtorno psíquico. Assim, a inclusão no mercado de trabalho perpassa por questões morais, sociais, de dignidade e é um símbolo de contrato social (JORGE; BEZERRA, 2004).

Em contrapartida, o afastamento do trabalho pode gerar sofrimento e vazio existencial, rupturas na identidade e até mesmo ausência de referência para os indivíduos. Além de baixa autoestima, sensação de abandono e de incompetência, frustração, culpa e instabilidade emocional. Em maior nível pode apresentar sentimento de exclusão, oscilação nas relações familiares e sociais, tentativas de suicídio e deterioração da saúde física (LIMA, 2007).

Goffman (1988) esclarece que ser diagnosticado com algum transtorno psíquico pode encaixar o indivíduo em um estigma de caráter individual. Trata-se da estigmatização por conta de algum traço apresentado, que o afasta ou exclui das relações sociais. Esse processo de afastamento dos considerados "loucos" ocorria, e ainda ocorre, de diversas maneiras. Por vezes mais explícitas como o depósito em manicômios, em outras de forma velada, como a desvalorização do indivíduo e o impedimento de retorno ou manutenção no mercado de trabalho. Isso ocorre devido aos resquícios do modelo manicomial no imaginário popular (SALLES; BARROS, 2013), produtores de representações sociais estereotipadas sobre o adoecimento psíquico. Portanto, é comum que esses indivíduos sejam vistos como incapazes de exercer funções e possuir responsabilidades profissionais, estigmatizando-os inclusive em direção à marginalização (JORGE; BEZERRA, 2004). Uma maneira de lidar com o estigma foi a mudança de terminologia para "em sofrimento psíquico", que se baseia na construção de representações e práticas sociais de democracia, inclusão e respeito às diferenças e direitos (AMARANTE, 1999).

Percebe-se a forma como o estigma influencia no cotidiano dos indivíduos em sofrimento psíquico, produzindo o que Goffman (1988) denomina como critérios de categorização da sociedade para definir os atributos que são considerados "normais" e "adequados" para determinadas funções e locais, resultando na exclusão dos "inadequados" e estigmatizados. Assim, é possível identificar que a inclusão e exclusão em diferentes contextos sociais influencia no processo de reabilitação psicossocial desses indivíduos. O trabalho como contexto de inclusão estabelece individualmente a possibilidade de contato interpessoal, proporciona status aos indivíduos e uma identidade social. Além de ser uma forma de ocupar o 
tempo, propiciar sensação de realização pessoal e garantir sustento financeiro (SALLES; BARROS, 2013).

Jorge e Bezerra (2004) identificaram em seu estudo que receber um diagnóstico de transtorno psíquico dificulta a inclusão no mercado de trabalho, por mais velado que possa ser o comportamento de evitação já cristalizado socialmente. Nesse contexto, muitos indivíduos buscam ajuda previdenciária como forma de sobrevivência, apesar de ser necessária a submissão à interdição judicial e a destituição de seus direitos civis para conseguir o benefício, no entanto, para muitas pessoas essa é a única forma de ter algum sustento financeiro. Apesar de a política de assistência, por vezes, ser instrumentalizada de forma capacitista, ela é um direito garantido pela Lei $\mathrm{n}^{\circ} 8.213$ (BRASIL, 1991), que assegura sobre o plano de benefícios da previdência social.

A falta de conhecimento e de proximidade com pessoas em sofrimento psíquico faz com que se reproduzam preconceitos. No imaginário popular circulam representações sociais de que os "loucos" são agressivos, perigosos ou incapazes. Dessa forma, sempre que há preconceito, há também alguma restrição que diminui a liberdade de escolha dos indivíduos (SALLES; BARROS, 2013).

O adoecimento psíquico decorrente da exclusão do mercado de trabalho suscita sentimento de rejeição, tristeza e incapacidade. Seja por não ter a própria renda, por depender de outras pessoas, ou por ter o desejo de acesso ao trabalho negado. Essa situação pode diminuir a sensação de dignidade, desencadear baixa autoestima e potencializar a depressão (JORGE; BEZERRA, 2004). A rejeição sofrida perpassa por questões de afetividade e gera desestruturação emocional devido à interrupção com o ambiente de trabalho, pode ainda acarretar rompimento do sujeito com os vínculos sociais, ligações comunitárias e com a possibilidade de estabelecer contato com o que é externo ao sujeito (JORGE; BEZERRA, 2004).

No entanto, estar ativo no mercado de trabalho também pode ser desencadeador de sofrimento psíquico. Diversos são os fatores que influenciam no adoecimento no ambiente laboral, como o estresse, alta carga de trabalho, acidentes, alterações psicossociais, desvalorização, baixa remuneração, dupla jornada e sentimento de frustração ou impotência (ALVIM et al., 2017).

O ambiente de trabalho surge socialmente como um espaço que define uma identidade social para os indivíduos, em uma concepção dialética, sua identidade está atrelada às suas experiências (COUTINHO; KRAWULSKI; SOARES, 2007). Portanto, o contexto de trabalho 
pode gerar saúde, mas de maneira antagônica, também pode desencadear o adoecimento psíquico e físico. Compreender como as pessoas reconhecem o mercado de trabalho é uma forma de se conscientizar sobre como esse espaço afeta os indivíduos. Diante dessa problemática, a Teoria das Representações Sociais é uma possibilidade para explorar o conhecimento de senso comum sobre fenômenos e objetos que envolvem a sociedade (MOSCOVICI, 2013).

Jodelet (2001) define as representações sociais como uma forma de dar significado ao mundo que nos cerca. Por meio delas é possível se localizar, ajustar, resolver problemas e tomar decisões. Contudo, devido à característica social do ser humano compartilha-se o mundo, ideias e representações, por esse motivo, as representações são consideradas sociais. As representações sociais sobre determinado fenômeno se instalam em valores variáveis ou sobre antigos saberes dos grupos nas quais são formuladas e, dessa forma, se tornam representativas por estarem conectadas a sistemas de pensamentos ideológicos ou culturais, assim como a condição social e individual dos sujeitos.

Moscovici (2013) aborda que as representações sociais convencionalizam objetos, acontecimentos e/ou pessoas, pois possibilita categorizá-los em modelos que sintetizam aspectos desses objetos, e assim viabiliza a interpretação das informações recebidas. É dessa forma que as representações dão significado a um objeto para determinado grupo, e esse grupo que partilha da mesma representação divide uma mesma visão de realidade, visão esta que pode ser diferente da visão de outros grupos e que influencia na dinâmica social (JODELET, 2001).

Com base nisso, é possível identificar que as representações sociais estão associadas a fenômenos cognitivos e ao pertencimento social, por meio da interiorização das práticas, comportamentos e valores do meio onde o indivíduo está inserido. Por esse motivo, as representações sociais são vistas como produto e processo da apropriação e da elaboração da realidade. É importante considerar que a Representação social é um saber prático que liga o sujeito a um objeto, em que toda representação é a representação de algo realizada por alguém, e tanto as características do indivíduo, quanto às características do objeto influenciarão na forma como este último é visto e representado (JODELET, 2001; MOSCOVICI, 2012).

Para Moscovici (2012) existem dois processos sociocognitivos essenciais para a formação das representações sociais: a objetificação e a ancoragem. A objetificação é um processo que torna concreto um conceito abstrato, por meio da transformação do conceito em imagem. Ao passo que a ancoragem é responsável pela assimilação de novos conhecimentos e informações a categorias já conhecidas pelo indivíduo (TRINDADE; SANTOS; ALMEIDA, 
2011). São esses processos a base para a elaboração das representações.

A representação social, portanto, é um saber prático e deve ser qualificado como tal (JODELET, 2001), pois ela se desenvolve a partir da experiência, sendo "produto" desta. As condições dessa experiência influenciarão na representação do sujeito sobre o objeto. Nesse sentido, buscar conhecer as experiências de trabalho de pessoas em sofrimento psíquico e compreender suas representações sociais sobre trabalho, viabiliza elucidar o estigma envolto nas relações sociais presentes nesse contexto.

Diante do exposto, o presente estudo tem como objetivo compreender as representações sociais sobre trabalho para pessoas em sofrimento psíquico.

\section{Método}

Trata-se de um estudo com delineamento em pesquisa-ação, caracterizada como qualitativa e exploratória, alicerçada na Teoria das Representações Sociais (MOSCOVICI, 2013). A pesquisa exploratória tem como objetivo possibilitar maior familiaridade ao problema de pesquisa e elucidar a temática (GIL, 2002). Quanto ao tipo de pesquisa, trata-se de uma pesquisa-ação caracterizada por envolver pesquisador e participantes ativamente durante todo o estudo de maneira colaborativa em prol do tema estudado (YIN, 2016).

As participantes do estudo foram 6 usuárias do Centro de Atenção Psicossocial II (CAPS II) do município de Criciúma/SC. Como critério de inclusão tinha-se como base que os/as participantes tivessem tido no mínimo 1 experiência de trabalho no mercado formal ou informal. Não havia critérios de inclusão ou exclusão acerca de gênero, porém, a população foi composta apenas por indivíduos de gênero feminino. Também não houve critérios quanto ao diagnóstico, sendo assim, o estudo abrangeu usuárias com transtornos de humor e personalidade, que correspondem a transtorno depressivo maior (2), transtorno afetivo bipolar (2), transtorno de personalidade borderline (1), esquizofrenia e transtornos associados (1).

As participantes da pesquisa foram selecionadas por amostragem por conveniência, pois se trata de um grupo já formado no CAPS (YIN, 2016). O grupo era conduzido por uma psicóloga em formato fechado, com a participação de 6 usuárias do serviço. A psicóloga responsável pelo grupo permitiu que a pesquisadora explicasse os objetivos da pesquisa e convidasse as usuárias para integrar o presente estudo, todas aceitaram participar.

O Centro de Atenção Psicossocial foi o local de realização da pesquisa por ser o serviço de saúde que recebe pessoas em sofrimento psíquico, e que atua na perspectiva de cuidado integral e reabilitação psicossocial. Além disso, é a instituição responsável pela articulação da 
rede de saúde mental do município (MOREIRA; ONOCKO-CAMPOS, 2017). A participação das usuárias do serviço na pesquisa consistiu em um grupo no formato de sociodrama, caracterizado por 5 (cinco) encontros com 1 (uma) hora de duração cada.

O primeiro encontro teve como objetivo relembrar as experiências de trabalho; o segundo encontro objetivou compreender como as participantes percebem o mercado de trabalho atualmente; o terceiro focou em como as participantes se imaginam no futuro no contexto laboral; o quarto encontro buscou entender os medos quanto ao reingresso no mercado de trabalho, e por fim, no último encontro foi realizada a despedida e o feedback.

Todos os encontros utilizaram como base o sociodrama, um método utilizado para pesquisas, tratamento de grupos e de relações intergrupais, em que o drama abordado é coletivo (CASTRO; CARDOSO; LEANDRO, 2020). Por esse motivo, os encontros iniciaram com um aquecimento a fim de "despertar" o tema do encontro para, posteriormente, serem abordados através de técnicas sociodramáticas, como a dramatização de suas experiências, criação de imagens, esculturas e o compartilhamento verbal dos conteúdos. Essas técnicas possibilitam compreender os processos de ancoragem e objetificação das representações sociais, e evidenciam as imagens e atitudes dos participantes sobre a temática investigada (CASTRO; CARDOSO; LEANDRO, 2020). Por meio dessa dinâmica a pesquisadora participou ativamente dos encontros, optando por técnicas e ferramentas sociodramáticas que se adequavam ao momento do grupo de modo a possibilitar a reflexão das participantes.

Os encontros foram gravados e posteriormente transcritos em um único corpus. A análise dos dados foi orientada pela técnica de análise de conteúdo do tipo categorial. Esta técnica de análise é utilizada na pesquisa qualitativa na medida em que trabalha com a frequência que certas informações e características aparecem nos discursos, relacionada a compreensão e inferência das causas e efeitos do discurso, caracterizada pela validação do conteúdo da fala dos indivíduos (BARDIN, 2011). O software Atlas.ti foi utilizado para auxiliar na análise, no entanto, ele não interpreta as informações, mas viabiliza a segmentação de texto, elaboração de códigos e anotações, permitindo uma melhor organização do corpus a ser analisado (FRIESE; SORATTO; PIRES, 2018).

A pesquisa foi submetida ao conselho do Comitê de Ética em Pesquisa da Universidade do Extremo Sul Catarinense e foi obtida a aprovação pelo parecer $n^{\circ} 2.625 .586$. O estudo respeitou os preceitos éticos legais que regem as pesquisas com seres humanos, sendo a participação condicionada à assinatura do Termo de Consentimento Livre e Esclarecido. O sigilo com a identidade das participantes foi garantido por meio da atribuição de um número a 
cada uma delas.

\section{Resultados e Discussão}

A pesquisa foi realizada com participantes do gênero feminino, com idade entre 30 e 62 anos. As mulheres passam por condições opressivas de existência, o que produz modos específicos de adoecer para elas. As experiências diárias que afetam a saúde abrangem majoritariamente a maternidade, a pressão normativa estética, a sexualidade e o trabalho reprodutivo (ALVES, 2017). Em razão de tais fatores o sofrimento psíquico parece ser mais frequentes entre as mulheres, com baixa escolaridade e rendimento, e que estão desempregadas (LEITE et al., 2017).

O recorte de classe social e gênero atrelado à saúde mental surge ao se considerar as desigualdades sociais, associadas a relações de opressão, poder, privilégio e subordinação. O adoecimento psíquico não surge apenas nas esferas sociais da classe trabalhadora com baixa renda, mas esse fator atrelado às desigualdades sociais vivenciadas nas relações de poder, envolvem sentimentos de humilhação, inferioridade, sensação de impotência e o adoecimento (LUDERMIR, 2008). Nesse sentido, as mulheres se destacam enquanto usuárias de serviços de saúde mental, interseccionando gênero com outros fatores de risco, como viver em situação de pobreza, condições econômicas e familiares de vida, trabalho precário e vivenciar exclusão social (CAMPOS; RAMALHO; ZANELLO, 2017).

Os dados gerados pelas participantes e analisados com o auxílio do software Atlas.ti foram agrupados em 7 categorias que incluem 31 códigos. Os códigos, por sua vez, são formados por segmentos de texto (quotations) que correspondem ao mesmo conteúdo geral da fala. A Tabela 1 apresenta as categorias, códigos e número de quotations em cada código.

Tabela 1 - Número de quotations vinculadas aos códigos e categorias

\begin{tabular}{lll}
\hline Categorias & Códigos & $\begin{array}{l}\mathrm{n}^{\text {o }} \\
(q)\end{array}$ \\
\hline $\begin{array}{l}\text { Aspectos adoecedores } \\
\text { do trabalho }\end{array}$ & $\begin{array}{l}\text { Ambiente adoecedor } \\
\text { Doação pessoal }\end{array}$ \\
& $\begin{array}{l}\text { Mercado de trabalho como produtor de medo } \\
\text { Cansaço derivado do trabalho excessivo }\end{array}$ & 9 \\
& Avaliação & 5 \\
& Trabalho como obrigação & 5 \\
& Trabalho infantil & 5 \\
Mercado de trabalho como gerador de & 4 \\
\hline \multirow{2}{*}{ Barbarói, Santa Cruz do Sul, n. 57, p.<44-64>,jul./dez. 2020}
\end{tabular}




\begin{tabular}{|c|c|c|}
\hline \multirow[t]{8}{*}{ 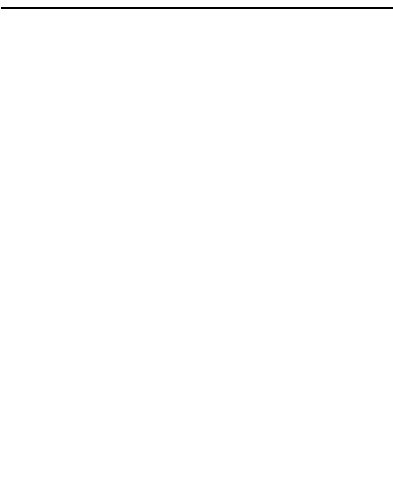 } & \multicolumn{2}{|l|}{ ansiedade } \\
\hline & Relações interpessoais negativas & 4 \\
\hline & Ausência de sonhos & 3 \\
\hline & Mercado de trabalho como espaço que exclui & 3 \\
\hline & Adoecimento na adolescência & 2 \\
\hline & Estigma & 2 \\
\hline & Tristeza derivada do trabalho doméstico & 2 \\
\hline & Obrigatoriedade do trabalho doméstico & 1 \\
\hline \multirow{5}{*}{$\begin{array}{l}\text { Significado do } \\
\text { Trabalho }\end{array}$} & Trabalho como obrigação & 5 \\
\hline & Trabalho como vocação & 3 \\
\hline & Necessidades pessoais & 2 \\
\hline & Obrigatoriedade do trabalho doméstico & 1 \\
\hline & Movimento & 1 \\
\hline \multirow{5}{*}{$\begin{array}{l}\text { Perspectivas de } \\
\text { Futuro }\end{array}$} & Insegurança ao retorno ao trabalho & 4 \\
\hline & Ressignificação & 4 \\
\hline & Retomada da Saúde & 3 \\
\hline & Retomada do trabalho doméstico & 3 \\
\hline & Retomada do lazer & 2 \\
\hline \multirow[t]{4}{*}{ Sonho de Infância } & Sonho de Infância associado ao cuidado & 4 \\
\hline & Ausência de sonhos & 3 \\
\hline & Sonho de infância relacionado à proteção & 2 \\
\hline & $\begin{array}{l}\text { Sonho de infância relacionado ao poder de } \\
\text { escolha }\end{array}$ & 1 \\
\hline \multirow{3}{*}{$\begin{array}{l}\text { Sonho de } \\
\text { Adolescência }\end{array}$} & Ausência de sonhos & 3 \\
\hline & $\begin{array}{l}\text { Sonho de adolescência relacionado ao poder } \\
\text { de escolha }\end{array}$ & 2 \\
\hline & Sonho de adolescência relacionado ao cuidado & 1 \\
\hline \multirow{3}{*}{$\begin{array}{l}\text { Imagens relacionadas } \\
\text { ao trabalho }\end{array}$} & Carteira assinada & 4 \\
\hline & Dinheiro como solucionador & 3 \\
\hline & Necessidades pessoais & 2 \\
\hline \multirow[t]{2}{*}{ Sociabilidade } & Relações interpessoais negativas & 4 \\
\hline & Relações interpessoais positivas & 2 \\
\hline
\end{tabular}

A primeira categoria denominada "Aspectos adoecedores do trabalho" é composta por 15 códigos, evidenciados na Tabela 1. Correspondem a falas que abordam o ingresso no mercado de trabalho ainda na infância, na condição de obrigação, o que mais tarde se transformou em uma intensa doação pessoal sem retorno ou reconhecimento. As participantes apontam que a adolescência foi o período em que a doença iniciou, e que o adoecimento foi fortalecido por um ambiente de trabalho difícil em decorrência das características físicas do 
ambiente e das relações interpessoais. Também foi relatada a dificuldade no processo de avaliação e seleção em decorrência do estigma da doença. Além disso, uma jornada de trabalho longa, excessiva e com metas inalcançáveis foi destacada como influenciadora do cansaço, tristeza, medo e ansiedade no ambiente de trabalho, fomentando o processo de exclusão.

A exclusão dos indivíduos em sofrimento psíquico advém de um contexto histórico em que devido ao estigma do "louco" a regra era a exclusão dos diferentes e inadequados. Principalmente, em razão ao modelo manicomial que transmitia para a população a mensagem de que essas pessoas eram perigosas ou incapazes, e deveriam ser afastadas e excluídas (SALLES; BARROS, 2013). Como demonstra a fala: "lá no mercado pelo meu aspecto físico, pelo meu pescoço, não me deram emprego e isso derruba a autoestima da gente. $\mathrm{O}$ mercado de trabalho é muito cruel e o ser humano é um bicho cruel" (participante 06, 30 anos, transtorno borderline).

Para as participantes da pesquisa acrescenta-se ainda que o adoecimento iniciou quando eram muito jovens. Dessa forma, o estigma as acompanha desde o ingresso no mercado de trabalho formal, considerando que desde a infância já realizavam o trabalho doméstico em sua própria casa, e na de casa de terceiros em situação informal devido à necessidade de remuneração. No Brasil, 54,4\% das crianças entre 5 e 17 anos se encontram em situação de trabalho infantil (IBGE, 2016). Enquanto os indivíduos que hoje estão na faixa-etária de 40 a 50 anos tiveram seu início no mercado de trabalho em média aos 14,5 anos (IBGE, 2011). Esse início precoce pode corroborar com a sobrecarga psíquica e adoecimento vivenciado pelos indivíduos.

A segunda categoria foi denominada "Significado do trabalho" e abrange 5 códigos, sendo eles: "Movimento", "Necessidades pessoais", "Obrigatoriedade do trabalho doméstico", "Trabalho como obrigação" e "Trabalho como vocação". Nesta categoria o trabalho é descrito como algo que movimenta, uma espécie de impulso para seguir a vida, uma vocação, algo que supostamente nasce com a pessoa. Em contraposição, outra perspectiva é a do trabalho como algo para suprir as necessidades pessoais de subsistência, relacionado a uma obrigação, um dever, e nesse contexto, abrange o trabalho doméstico. Cabe ressaltar que a maioria dos participantes (4) iniciaram suas experiências por meio do trabalho doméstico ainda na infância, o que corrobora a ideia do trabalho como obrigação, tendo em vista que durante a infância desejavam brincar e estudar. Como demonstra o trecho a seguir:

A mãe saia pra trabalhar fora e eu com 7 anos cuidava dos meus irmãos e da casa, [...] eu já era meio neurótica desde pequenininha, tinha coisa que eu não conseguia fazer, mas dava um jeito, [...] a única coisa que meus irmãos precisavam fazer era tirar água do poço. Então com 13 anos eu resolvi trabalhar fora, porque eu não tinha nada, não 
tinha um calçado pra colocar no pé e quase morria trabalhando em casa de graça (participante 03, 53 anos, transtorno afetivo bipolar).

A partir da fala da participante é possível identificar o estereótipo do trabalho doméstico associado como "naturalmente" feminino, pois apesar de ter mais crianças na casa não havia divisão das atividades domésticas. No ano de 2005 mais de 37 milhões de mulheres/crianças com mais de 10 anos tinham como atividade o cuidado doméstico, dos familiares, enfermos, filhos e maridos (MELO; CASTILHO, 2009). Ainda hoje, apesar de a realidade brasileira contemplar as mulheres no mercado de trabalho formal, majoritariamente ainda são elas as responsáveis pelo trabalho reprodutivo. Sendo que $95 \%$ das mulheres adultas realizam esse trabalho não pago, enquanto entre os homens esse percentual é de 55\% (IPEA, 2017). Dessa forma, há a sobrecarga devido à dupla jornada de trabalho, acréscimo de responsabilidades e diminuição do tempo de descanso e lazer, que podem representar outro fator adoecedor.

O trabalho, de acordo com Spinelli (2015), pode ter como finalidade ser fonte de sobrevivência, mas também ser uma forma de obter prazer e realização pessoal através das atividades desempenhadas. No trecho de fala apresentado pode-se perceber o trabalho como forma de garantir a sobrevivência, relacionado primeiramente à vivência diária e, consequentemente, à necessidade de dinheiro. O salário possui diversas significações, as concretas são caracterizadas por pagar dívidas e sustentar a família, enquanto as não concretas carregam sonhos e projetos possíveis de realizações. No entanto, o salário quando insuficiente possui seu lado negativo na medida em que caracteriza todas as limitações materiais pelas quais o sujeito passa, torna-se representante material das dificuldades vividas no campo aquisitivo (DEJOURS, 1992).

A terceira categoria intitulada "Perspectivas de futuro" abrange igualmente 5 códigos, sendo eles: "Insegurança no retorno ao trabalho", "Ressignificação", "Retomada da saúde", "Retomada do lazer" e "Retomada do trabalho doméstico". As falas que compõem essa categoria expõem a impossibilidade de retorno ao mercado de trabalho devido aos medos, ansiedades e experiências anteriores negativas. Como perspectiva de futuro o trabalho doméstico aparece atrelado à necessidade de se sentir capaz, possibilitando satisfação pessoal. Em outro polo, há participantes cujo futuro não abrange o retorno ao mercado de trabalho, mas o restabelecimento da saúde para voltar a realizar atividades cotidianas que lhes eram prazerosas, e realizar planos adiados pelo adoecimento. Ao final da atividade proposta pela pesquisadora, algumas participantes ressignificaram sua relação com o trabalho por meio da associação de experiências positivas, até então esquecidas. No entanto, persistem as preocupações quanto a impossibilidade de retorno ao trabalho, como exemplificado na fala a Barbarói, Santa Cruz do Sul, n. 57, p.<44-64>, jul./dez. 2020 
seguir:

Eu teria insegurança total agora, porque eu não me sinto mais capaz, não sei se estou fazendo certo, se estou fazendo errado. Porque agora eu estou mais pra ser comandada, depois que eu fiquei doente, antes eu era muito ativa, comandava (participante 05, 57 anos, transtorno afetivo bipolar).

De acordo com Nigatu et al. (2017) o retorno ao mercado de trabalho envolve características pessoais, clínicas e fatores psicossociais, como o tempo de afastamento e a gravidade dos sintomas. Dessa forma, pessoas que tiveram experiências negativas no mercado de trabalho são menos propensas a retornar, pois, a autoeficácia, no sentido de acreditar em sua capacidade de voltar ao trabalho, é importante para um retorno bem-sucedido. No entanto, a maioria das participantes da pesquisa trazem em suas falas o sentimento de incapacidade diante da possibilidade de retomada ao trabalho.

Para as participantes, o trabalho doméstico/reprodutivo está relacionado ao sentimento de valia e de autonomia. Sentir-se útil e saudável na medida em que conseguem retomar as atividades que realizavam para si mesmas e suas famílias antes do processo de adoecimento. Como demonstra o trecho:

Em 3 anos eu me vi na minha casa, limpando, coisa que eu não consigo fazer hoje e a minha foto era eu limpando minha casa, varrendo, tirando o pó, porque é estrada de chão e entra muita poeira, estava bem limpa a minha casa, porque hoje não é assim (participante 01, 42 anos, esquizofrenia e transtornos associados).

O trecho traz um importante componente analítico relacionado ao gênero, visto que muitas mulheres são educadas para o trabalho doméstico e atrelam serviços reprodutivos a satisfação pessoal. O gênero, aqui entendido a partir de Joan Scott (1995), é um sistema social que tem como função significar relações de poder. No contexto do trabalho, a desvalorização do trabalho reprodutivo/doméstico em detrimento do trabalho produtivo/assalariado, junto a estereótipos cristalizados de feminilidade, corrobora com a manutenção das mulheres em hierarquias sociais inferiores aos homens. O modelo de sociedade patriarcal fez emergir representações sociais da dona de casa e cuidadora, herança da era vitoriana (SCOTT, 1995), que ainda hoje produz efeitos na subjetividade das mulheres.

A quarta categoria nomeada "Sonho de infância" apresenta 4 códigos, sendo eles: "Ausência de sonhos", "Sonho de infância associado ao cuidado", "Sonho de infância relacionado à proteção" e "Sonho de infância relacionado ao poder de escolha". A ausência de sonhos citada pelas participantes se contrapõe a ideia de trabalho como vocação apresentada na primeira categoria. Percebem-se as diferenças encontradas nesta categoria a partir das falas: "Hoje eu não consigo nem ouvir falar de salão e a minha profissão é essa, pois era minha 
vocação desde criancinha, desde pequena eu já vivia pendurada em cima das mulheres puxando os cabelos, era minha vocação." (participante 05, 57 anos, transtorno afetivo bipolar). E: "Não lembro nada da minha infância, não sei o que eu queria ser quando crescesse. Na adolescência eu continuava sem saber, sei lá, eu era estranha, não sonhava, me dá até vontade de chorar, não tinha vontade de ser nada." (participante 03, 53 anos, transtorno afetivo bipolar).

Nesse contexto, enquanto algumas participantes apresentam sonhos desde a infância e os seguem, outras afirmam não possuir sonhos nem mesmo na infância e, por esse motivo, não ter um objetivo ou meta a ser cumprida. Os demais sonhos de infância estão relacionados à profissão que desejavam exercer quando adultos e, concomitantemente, ao que esperam receber afetivamente. Assim, enquanto algumas trazem como profissão a enfermagem, outras afirmam que gostariam de atuar na defesa civil, polícia ou como juízas. Possivelmente vinculado à imagem de algo que lhes eram desejados, como proteção, cuidado e poder de escolha (GODOI; CARGNIN; UCHÔA, 2017). Os trechos apresentados vêm ao encontro da teoria marxista sobre o trabalho quando Marx (2016) afirma que o trabalho dá sentido à vida. Logo, para além da produção de mais-valia (MARX, 2010), permite ao indivíduo projetar metas e elaborar sonhos.

A quinta categoria corresponde ao "Sonho de adolescência" e abarca 3 códigos: "Ausência de sonhos", "Sonho de adolescência associado ao cuidado" e "Sonho de adolescência relacionado ao poder de escolha". Profissões similares à categoria anterior são relatadas, porém, não surge a ideia de proteção. Pode estar relacionada à busca por autonomia que surge na adolescência conforme se encaminham para a independência adulta, que geralmente vem acompanhada da independência financeira, ou seja, relacionado ao trabalho para garantir sustento e autossuficiência (HABIGZANG; DINIZ; KOLLER, 2014).

No entanto, quando não se possui um objetivo específico além da independência, ou mesmo quando as condições financeiras atreladas a classe social a qual pertence não lhe permitem escolhas, o indivíduo pode aceitar o trabalho que surgir e que nem sempre possui condições adequadas. Além disso, muitos ambientes de trabalho são caracterizados pela despersonalização dos trabalhadores, que pode estimular o adoecimento (DEJOURS, 1992). Esse adoecer pode ser representado pelo seguinte trecho: "eles faziam muito bullying e quando eu vi, eu já estava caindo" (participante 01, 42 anos, esquizofrenia e transtornos diversos), que faz correlação com os códigos: sociabilidade e relações interpessoais negativas.

A sexta categoria traz as "Imagens relacionadas ao trabalho" e é composta pelos códigos: "Carteira assinada", "Dinheiro como solucionador" e "Necessidades pessoais". Nesta categoria a concretude do trabalho se dá mediante a imagem da assinatura da carteira e da 
sensação de estabilidade que isso fornece. O momento da assinatura da carteira é destacado pelos participantes como um ápice na experiência de trabalho. Por outro lado, a imagem do dinheiro também surge como algo que auxiliaria no processo de enfrentamento das dificuldades, tendo em vista que dá conta das necessidades pessoais, desde as básicas até as supérfluas. Contudo, o dinheiro não surge como consequência do trabalho, mas como algo que as afastariam dele. Este dinheiro é descrito como oriundo de jogos de azar, associado à diversão e lazer.

O modelo social capitalista faz com que o dinheiro consolide as atividades sociais e funcionais desempenhadas, pois é por meio dele que se estabelece um valor social para o trabalhador. Complementarmente, o dinheiro também concretiza a imaterialidade de trabalhos que não produzem algo concreto, palpável (HARVEY, 2017). Em uma sociedade baseada no consumo, dentre as diversas funções sociais que podem existir para o dinheiro o fator "felicidade" surge quando associado à busca por novas experiências, lazer e cumprimento de metas próprias (LAUER-LEITE et al., 2014).

A carteira assinada surge como garantia do alcance deste dinheiro. $\mathrm{O}$ trabalho informal traz ao trabalhador uma invisibilidade social, o não reconhecimento por parte do estado de seu papel de trabalhador (IRIART et al., 2008). Identificado no seguinte trecho: "Quando eu fiz 16 anos já podia assinar carteira, então eu peguei em empresa" (participante 03, 53 anos, transtorno afetivo bipolar).

O fato de a carteira de trabalho estar presente em diversas falas pode também estar relacionado à aposentadoria, isto é, ao tempo de carteira assinada que ainda falta para conseguir aposentar-se e então, o descanso e lazer esperados. Apesar do baixo valor monetário na maioria dos casos, a aposentadoria mostra-se como um fator financeiro útil para os gastos com as necessidades básicas, caracterizado pela estabilidade de possuírem uma renda mensal fixa para corroborar com o momento de descanso e de cuidado do lar (ARAÚJO; BELO; RESENDE, 2016).

A última categoria denominada "Sociabilidade" abarca "Relações interpessoais negativas" e "Relações interpessoais positivas". Há participantes que apresentam sentimento de ambivalência sobre as relações interpessoais no trabalho, enquanto outras participantes se encontram polarizadas sobre a questão, considerando a sociabilidade como algo que mantém o trabalho quando os vínculos são fortalecidos, ou que afasta da ocupação quando os vínculos estão adoecidos. Contradições demonstradas na fala: "Tu encontra amigos lá dentro, pessoas que são queridas, generosas, solidárias, pessoas que convivem contigo e que tem bom 
relacionamento, mas a quantidade de pessoas ruins e que gostam de fazer o mal pelos outros é muito maior." (participante 06, 30 anos, transtorno borderline).

Com base nessas contradições relacionais o estudo de Brito (2015) apresenta que relações interpessoais negativas estão associadas à elevação dos sintomas depressivos, diminuição da autoestima e participação social, e na presença de problemas interpessoais, desta forma, prejudicando outras esferas da vida dos indivíduos. No entanto, relações sociais positivas auxiliam na promoção de bem-estar, desenvolvimento individual e coletivo no ambiente de trabalho (SILVA; FURTADO; ZANINI, 2015).

No que se refere as representações sociais, Moscovici (2012) concebe os processos de ancoragem e objetificação essenciais para sua compreensão. Sendo as representações sociais do trabalho das participantes ancoradas em suas experiências ocupacionais, principalmente nas dificuldades dos relacionamentos interpessoais e de sua inserção ser derivada da obrigação, sem corresponder aos seus sonhos. A objetificação das representações de trabalho, ou seja, a concretização de um conceito abstrato (TRINDADE; SANTOS; ALMEIDA, 2011), se deu através da imagem do dinheiro e da carteira assinada.

Moscovici (2012) ainda considera que as representações sociais possuem três dimensões: informação, imagem e atitude. A dimensão da informação corresponde aos conhecimentos sobre determinado fenômeno ou objeto (Moscovici, 2012), sendo que para as participantes as informações advêm de suas experiências profissionais. A imagem é o conteúdo concreto da representação, seu campo (Moscovici, 2012), no presente estudo, o mercado de trabalho visto como um ambiente adoecedor. Por fim, a atitude se refere a dimensão da relação estabelecida com o fenômeno da representação (Moscovici, 2012). Para as participantes se destaca uma atitude desfavorável por conta da insegurança sentida frente à possibilidade de retorno, sendo o foco na retomada da saúde, para então usufruir do tempo e da saúde para o lazer.

\section{Considerações Finais}

O presente estudo buscou investigar as Representações sociais do trabalho para pessoas em sofrimento psíquico, por meio da compreensão dos processos de ancoragem e objetificação. Dessa forma, percebeu-se ao longo dos encontros e pela análise realizada, que as representações sociais das participantes estavam ancoradas em suas próprias experiências de vida, objetificadas na imagem do dinheiro como garantia de subsistência, cercadas de lembranças negativas, mas também fortalecedoras na medida em que foram ressignificadas. 
Os conteúdos que emergiram foram segmentados em 7 categorias pela análise de conteúdo, que sustentam os objetivos da pesquisa. Foi possível identificar que as participantes concebem o ambiente de trabalho como um local adoecedor, devido às situações pelas quais passaram. Bem como, o trabalho representa para elas tanto uma obrigação, quanto vocação, apesar de nenhuma ter como perspectiva de futuro retornar ao mundo do trabalho por terem como foco a restituição da saúde.

Evidencia-se o recorte de classe e gênero pela pesquisa ter em sua totalidade participantes mulheres que iniciaram no mundo do trabalho na infância ou adolescência. Esse início precoce ocorre devido à necessidade de dinheiro para subsistência, ou no trabalho reprodutivo em virtude do suposto lugar natural das mulheres em atividades domésticas. Sendo essa carga intensa e contínua um dos influenciadores para o adoecimento psíquico.

Este estudo contribuiu para compreender o papel do trabalho na vida de indivíduos estigmatizados socialmente e permitiu elucidar sua influência no processo de adoecimento. Os dados analisados também propiciaram uma importante reflexão a respeito do modelo ocupacional atual e suas diversas formas de opressão, bem como a importância de promover saúde nesses espaços.

Considera-se necessário realizar mais investigações a respeito do tema com esse público, ampliando o número de participantes e variáveis investigadas, como os segmentos de mercado de atuação das participantes e aprofundar a discussão de gênero, classe e suas interseccionalidades. No entanto, esta pesquisa forneceu importantes informações para demonstrar a necessidade de ações de conscientização sobre o adoecimento no ambiente de trabalho, e que sejam efetivadas propostas nesses ambientes que visem a promoção da saúde e prevenção do adoecimento.

\title{
"THE LABOR MARKET IS VERY CRUEL": SOCIAL REPRESENTATIONS OF WOMEN IN PSYCHOLOGICAL DISTRESS
}

\begin{abstract}
The present study aims to investigate social representations about work for people in psychological comfort. This is a research, with a qualitative and exploratory approach, developed by a sociodrama group not formatted and anchored in the Theory of Social Representations. Five meetings were held with duration of 1 hour each, with the participation of 6 users of a Psychosocial Care Center. Data analysis was performed as a categorical content analysis, as an aid to Atlas.ti software. The results will show 7 categories that involve the adolescent aspects of work, meaning of work, future perspectives, childhood and adolescence, images related to work and socialization. The social representations of work for participants are rooted in their negative work experiences and are objectified in the image of money, which guarantees their survival.
\end{abstract}


Keywords: Social Representation. Labour. Mental Health.

\title{
"EL MERCADO LABORAL ES MUY CRUEL": REPRESENTACIONES SOCIALES DE MUJERES EN ANGUSTIA PSICOLÓGICA
}

\author{
Resumen \\ El presente estudio tiene como objetivo investigar las representaciones sociales sobre el \\ trabajo para personas con comodidad psicológica. Esta es una investigación, con un enfoque \\ cualitativo y exploratorio, desarrollada por un grupo no sociodrama no formateado y anclado \\ en la Teoría de las Representaciones Sociales. Se realizaron cinco reuniones con una duración \\ de 1 hora cada una, con la participación de 6 usuarios de un Centro de Atención Psicosocial. \\ El análisis de datos se realizó como un análisis de contenido categórico, como una ayuda para \\ el software Atlas.ti. Los resultados mostrarán 7 categorías que involucran los aspectos \\ adolescentes del trabajo, el significado del trabajo, las perspectivas futuras, la infancia y la \\ adolescencia, las imágenes relacionadas con el trabajo y la socialización. Las \\ representaciones sociales del trabajo para los participantes están enraizadas en sus \\ experiencias laborales negativas y están objetivadas a la imagen del dinero, lo que garantiza \\ su supervivencia.
}

Palabras clave: Representación Social. Trabajo. Salud Mental.

\section{REFERÊNCIAS}

ALVES, T. M. Gênero e saúde mental: algumas interfaces. Contextos Working Paper, Minho, v. 2, n. 3, p. 1-22, jul. 2017. Disponível em:

http://repositorium.sdum.uminho.pt/handle/1822/46599. Acesso em: 10 fev. 2020.

ALVIM, C. C. E. et al. Relação entre processo de trabalho e adoecimento mental da equipe de enfermagem. Revista Fluminense de Extensão Universitária, [s.l.], v. 7, n. 1, p. 12-16, jan./jun. 2017. Disponível em:

http://editora.universidadedevassouras.edu.br/index.php/RFEU/article/view/918. Acesso em: 09 mar. 2020.

AMARANTE, P. Manicômio e loucura no final do século e do milênio. In: FERNANDES, M. I. (Org.). Fim de século: ainda manicômios? São Paulo: IPUSP, 1999. p. 47-56.

ANDRADE, T. Mulheres no mercado de trabalho: onde nasce a desigualdade? Estudo técnico da Câmara dos Deputados. Brasília, DF: Câmara dos Deputados, 2016. Disponível em: https://www2.camara.leg.br/atividade-legislativa/estudos-e-notas-tecnicas/publicacoesda-consultoria-legislativa/areas-da-conle/tema7/2016_12416_mulheres-no-mercado-detrabalho_tania-andrade. Acesso em: 10 fev. 2020.

ARAÚJO, J. L.; BELO, R. P.; RESENDE, J. W. R. Trabalho e Envelhecimento na Contemporaneidade: uma análise acerca da representação social da aposentadoria. Perspectivas em Psicologia, Uberlândia, v. 20, n. 1, p. 120-144, jan./jun. 2016. Disponível em: http://www.seer.ufu.br/index.php/perspectivasempsicologia/article/view/35593. Acesso em: 20 mar. 2020.

BARDIN, L. Análise de Conteúdo. Lisboa: Edições 70, 2011.

BRASIL. Lei n 8.213, de 24 de julho de 1991. (1991). Dispõe sobre os Planos de Benefícios Barbarói, Santa Cruz do Sul, n. 57, p.<44-64>, jul./dez. 2020 
da Previdência Social e dá outras providências. Diário Oficial [da] República Federativa do Brasil, Brasília, DF, 24 jul. 1991. Disponível em:

http://www.planalto.gov.br/ccivil_03/leis/18213cons.htm. Acesso em: 07 mar. 2020.

BRITO, J. F. C. O efeito moderador do funcionamento psicossocial na relação entre a qualidade das relações interpessoais e a sintomatologia depressiva, numa amostra de jovens portugueses. 2015. 37 f. Dissertação (Mestrado Integrado em Psicologia Clínica e da Saúde). Faculdade de Psicologia e de Ciências da Educação, Coimbra, Portugal, 2015.

CAMPOS, I. O.; RAMALHO, W. M.; ZANELLO, V. Saúde mental e gênero: O perfil sociodemográfico de pacientes em um centro de atenção psicossocial. Estudos de Psicologia, Natal, v. 22, n. 1, p. 68-77, mar. 2017. Disponível em: http://pepsic.bvsalud.org/scielo.php?script=sci_arttext\&pid=S1413-294X2017000100008. Acesso em: 15 mar. 2020.

CASTRO, A.; CARDOSO, A. S.; LEANDRO, M. O sociodrama como método de captação das representações sociais. Revista de Psicologia, Fortaleza, v. 11, n. 1, p. 151-155, jan./jun. 2020. Disponível em: http://www.periodicos.ufc.br/psicologiaufc/article/view/41105. Acesso em: 20 fev. 2020.

COUTINHO, M. C.; KRAWULSKI, E.; SOARES, D. H. P. Identidade e trabalho na contemporaneidade: repensando articulações possíveis. Psicologia \& Sociedade, [online], v. 19, n. spe, p. 29-37, 2007. Disponível em: https://www.scielo.br/scielo.php?pid=S0102$71822007000400006 \&$ script=sci_abstract\&tlng=pt. Acesso em: 20 mar. 2020.

DEJOURS, C. A loucura do trabalho: Estudo da psicopatologia do trabalho. São Paulo: Cortez; Oboré, 1992.

FEDERICI, S. Calibã e a bruxa: mulheres, corpo e acumulação primitiva. São Paulo: Editora Elefante, 2018.

FRIESE, S.; SORATTO, J.; PIRES, D. Carrying out a computer-aided thematic content analysis with ATLAS. ti.MMG Working Paper, Göttingen, v. 18, n. 2, p. 1-30, 2018. Disponível em: https://pure.mpg.de/pubman/faces/ViewItemOverviewPage.jsp?itemId=item_2582914_3. Acesso em: 17 fev. 2020.

GIL, A. C. Como elaborar projetos de pesquisa. 4. ed. São Paulo: Atlas, 2002.

GOGOI, C. K.; CARGNIN, F. R. G.; UCHÔA, A. G. F. Manifestações inconscientes na relação líder-liderado: contribuições da teoria psicanalítica aos estudos organizacionais. Cadernos EBAPE.BR. [online], v. 15, n. 3, p. 599-614, 2017. Disponível em: https://www.scielo.br/scielo.php?pid=S167939512017000300599\&script=sci_abstract\&tlng=pt. Acesso em: 17 fev. 2020.

GOFFMAN, E. Estigma: Notas sobre a manipulação da identidade deteriorada. 4 ed. Rio de Janeiro: Guanabara Koogan, 1988.

HABIGZANG, L. F.; DINIZ, E.; KOOLER, S. H. Trabalhando com adolescentes: teoria e intervenção psicológica. Porto Alegre: Artmed, 2014.

Barbarói, Santa Cruz do Sul, n. 57, p.<44-64>,jul./dez. 2020 
HARVEY, D. 17 contradições e o fim do capitalismo. São Paulo: Boitempo Editorial, 2017.

IBGE. INSTITUTO BRASILEIRO DE GEOGRAFIA E ESTATÍSTICA. Pesquisa Nacional por Amostra a Domicílio. Rio de Janeiro: IBGE, 2011.

IBGE. INSTITUTO BRASILEIRO DE GEOGRAFIA E ESTATÍSTICA. Pesquisa Nacional por Amostra a Domicílio. Rio de Janeiro: IBGE, 2016.

IPEA. INSTITUTO DE PESQUISA ECONÔMICA E APLICADA. Retratos da desigualdade de gênero e raça - 1995 a 2015. Brasília, DF: IPEA, 2017.

IRIART, J. A. B. et al. Representações do Trabalho informal e dos riscos à saúde entre trabalhadores da construção civil. Ciência e Saúde Coletiva, [online], v. 13, n. 1, p. 165-174, 2008. Disponível em: https://www.scielo.br/scielo.php?pid=S1413-

$81232008000100021 \&$ script=sci_abstract\&tlng=pt. Acesso em: 18 mar. 2020.

JODELET, D. (2001). Representações sociais: Um domínio em expansão. In: JODELET, D. (Org.). Rio de Janeiro: EdUERJ, 2001. p. 31-61.

JORGE, M. S. B.; BEZERRA, M. L. R. Inclusão e Exclusão Social do Doente Mental no Trabalho: Representações Sociais. Texto e Contexto Enfermagem, Florianópolis, v. 13, n. 4, p. 551-558, 2004. Disponível em: https://www.scielo.br/scielo.php?pid=S0104-

07072004000400007\&script=sci_abstract\&tlng=pt. Acesso em: 15 mar. 2020.

LAUER-LEITE, I. D. et al. Valores Humanos e significado do dinheiro: um estudo correlacional. Psico, Porto Alegre, v. 45, n. 1, p. 15-25, jan./mar. 2014. Disponível em: http://revistaseletronicas.pucrs.br/ojs/index.php/revistapsico/article/view/12243. Acesso em: 23 fev. 2020.

LEITE, J. F. et al. Condições de vida, saúde mental e gênero em contextos rurais: um estudo a partir de assentamentos de reforma agrária do Nordeste brasileiro. Avances en Psicología Latinoamericana, Bogotá (Colombia), v. 35, n. 2, p. 301-316, 2017. Disponível em: http://www.scielo.org.co/pdf/apl/v35n2/1794-4724-apl-35-02-00301.pdf. Acesso em: 27 fev. 2020.

LIMA, M. E. A. Trabalho e identidade: uma reflexão à luz do debate sobre a centralidade do trabalho na sociedade contemporânea. Educação \& Tecnologia, Belo Horizonte, v. 12, n. 3, p. 05-09, set./dez. 2007. Disponível em: https://seer.dppg.cefetmg.br/index.php/revistaet/article/view/107/109. Acesso em: 03 mar. 2020.

LUDERMIR, A. B. Desigualdades de classe e gênero e saúde mental nas cidades. Physis, Rio de Janeiro, v. 18, n. 3, p. 451-467, 2008. Disponível em: https://www.scielo.br/scielo.php?pid=S0103$73312008000300005 \&$ script=sci_abstract\&tlng=pt. Acesso em. 07 mar. 2020.

MARX, K. Manuscritos econômico-filosóficos. 7. ed. São Paulo: Boitempo, 2010.

MARX, K. O capital: Crítica da economia política. 34. ed. Rio de Janeiro: Civilização Brasileira, 2016. 
MELO, H. P.; CASTILHO, M. Trabalho reprodutivo no Brasil: quem faz? Revista Economia Contemporânea, Rio de Janeiro, v. 13, n. 1, p. 135-158, jan./abr. 2009. Disponível em: https://www.scielo.br/scielo.php?pid=S1415-

98482009000100006\&script=sci_abstract\&tlng=pt. Acesso em: 17 mar. 2020.

MOREIRA, M. I. B.; ONOCKO-CAMOS, R. T. Ações de saúde mental na rede de atenção psicossocial pela perspectiva dos usuários. Saúde e sociedade, São Paulo, v. 46, n. 2, p. 462474, 2017. Disponível em: https://www.revistas.usp.br/sausoc/article/view/134789/130555. Acesso em: 27 fev. 2020.

MOSCOVICI, S. A psicanálise, sua imagem e seu público. Petrópolis, RJ: Vozes, 2012.

MOSCOVICI, S. Representações sociais: Investigações em psicologia social. 10. ed. Petrópolis, RJ: Vozes, 2013.

NIGATU, Y. T. et al. Prognostic factors for return to work of employees with common mental disorders: a meta-analysis of cohort studies. Soc Psychiatry Psychiatr, [s.l.], v. 52, n. 10, p. 1205-1215, jun. 2017. Disponível em: https://pubmed.ncbi.nlm.nih.gov/28577211/. Acesso em: 10 mar. 2020.

SALLES, M. M.; BARROS, S. Representações sociais de usuários de um Centro de Atenção Psicossocial e pessoas de sua rede sobre doença mental e inclusão social. Saúde e Sociedade, v. 22, n. 4, p. 1059-1071, 2013. Disponível em: https://www.scielo.br/scielo.php?pid=S010412902013000400009\&script=sci_abstract\&tlng=pt. Acesso em: 15 mar. 2020.

SCOTT, J. Gênero: uma categoria útil de análise histórica. Educação e realidade, [s.l.], v. 2, n. 20, p. 71-99, jul./dez. 1995. Disponível em:

https://seer.ufrgs.br/educacaoerealidade/article/view/71721/40667. Acesso em: 20 mar. 2020.

SILVA, A. C. C. J.; FURTADO, J. H.; ZANINI, R. R. Um estudo sobre a Qualidade de Vida no Trabalho e os fatores associados. Iberoamerican Journal of Industrial Engineering, Florianópolis, v. 7, n. 14, p. 182-200, 2015. Disponível em:

http://incubadora.periodicos.ufsc.br/index.php/IJIE/article/view/3669/pdf_111. Acesso em: 18 mar. 2020.

SPINELLI, J. G. Os sentidos de trabalho para mulheres atuantes no mercado financeiro: Entre a vocação e a remuneração. 2015. 100 f. Dissertação (Programa de Pós-graduação em Administração de Empresa). Pontifícia Universidade Católica do Rio de Janeiro, Rio de Janeiro, 2015.

TRINDADE, Z.; SANTOS, F.; ALMEIDA, A. (2011). Ancoragem: notas sobre consensos e dissensos. In: ALMEIDA, A. M. O.; SANTOS, M. F. S.; TRINDADE, Z. A. (Orgs.). Teoria das Representações Sociais: 50 anos. 2. ed. Brasília: Technopolitik, 2011. p. 101-122.

YIN, R. K. Pesquisa qualitativa do início ao fim. Porto Alegre: Penso, 2016.

Data de recebimento: $31 / 05 / 2020$

Data de aceite: 17/08/2020

Barbarói, Santa Cruz do Sul, n. 57, p.<44-64>,jul./dez. 2020 


\section{Sobre os autores:}

Marieli Mezari Vitali é Mestranda vinculada ao Programa de Pós-Graduação em Psicologia da Universidade Federal de Santa Catarina (UFSC). Bacharel em Psicologia pela Universidade do Extremo Sul Catarinense (UNESC). Endereço Eletrônico: marielimezari@gmail.com

Camila Maffioleti Cavaler é Mestranda vinculada ao Programa de Pós-Graduação em Psicologia da Universidade Federal de Santa Catarina (UFSC). Bacharel em Psicologia pela Universidade do Extremo Sul Catarinense (UNESC). Endereço Eletrônico: camilamaffioleti@hotmail.com

Jacks Soratto é Professor vinculado ao Programa de Pós-Graduação e Residência Multiprofissional em Saúde Coletiva da Universidade do Extremo Sul Catarinense (UNESC). Doutor em Enfermagem pela Universidade Federal de Santa Catarina (UFSC). Endereço Eletrônico: jacks@unesc.net

Amanda Castro é Professora vinculado ao departamento de Psicologia da Universidade do Extremo Sul Catarinense (UNESC) e Universidade Estácio de Sá. Doutora em Psicologia pela Universidade Federal de Santa Catarina (UFSC). Endereço Eletrônico: amandacastrops@gmail.com 